\title{
Органы государственной безопасности советской России и обеспечение экономической безопасности страны, 1921-1928 гг.: механизм, проблемы, противоречия (на материалах Курской и Воронежской губерний)
}

\author{
Богданов С.В., Остапюк В.Г. \\ Белгородский государственный национальный исследовательский университет, \\ Россия, 308015, г. Белгород, ул. Победы, 85 \\ E-mail: bogdanov@bsu.edu.ru
}

\begin{abstract}
Аннотация. Статья посвящена становлению и развитию государственной политики обеспечения безопасности в экономической сфере после прихода к власти большевистского правительства. Анализируются особенности развития политики экономической безопасности в один из самых противоречивых периодов развития Советского государства - годы реализации новой экономической политики. Выявлены факторы, способствовавшие криминализации экономических отношений, широкому распространению коррупции в советском обществе. Рассматрены основные мероприятия государственных органов по обеспечению экономической безопасности. Выявлены проблемы и противоречивый характер механизмов обеспечения экономической безопасности, использовавшихся в 1920-е годы.
\end{abstract}

Ключевые слова: экономическая безопасность, экономические преступления, ОГПУ, нэп.

Для цитирования: Богданов С.В., Остапюк В.Г. 2020. Органы государственной безопасности советской России и обеспечение экономической безопасности страны, 1921-1928 гг.: механизм, проблемы, противоречия (на материалах Курской и Воронежской губерний). NOMOTHETIKA: Философия. Социология. Право. 45 (2): 307-314. DOI 10.18413/2712-746X-2020-44-2-307-314

\section{State security bodies of soviet Russia and ensuring economic security of the country, 1921-1928: mechanism, problems, contradictions (on materials of Kursk and Voronezh provinces)}

\author{
Sergey V. Bogdanov, Vladimir G. Ostapyuk \\ Belgorod National Research University, \\ 85 Pobeda St, Belgorod, 308015, Russia \\ E-mail: bogdanov@bsu.edu.ru
}

\begin{abstract}
The article is devoted to the formation and development of the state policy of security in the economic sphere after the Bolshevik government came to power. The author analyzes the features of the development of economic security policy in one of the most controversial periods of the development of the Soviet state - the years of implementation of the new economic policy. The years of the implementation of the new economic policy (1921-1928) in Soviet Russia revealed a large number of socio-economic, political, legal and ideological contradictions. The revival of entrepreneurial activity inevitably entailed property and social differentiation. The inevitable bureaucratization of the Soviet system of government created favorable conditions for the theft of state and public property. The author identifies the factors that contributed to the criminalization of economic relations and the widespread corruption in Soviet society. The main activities of state bodies to ensure economic security are considered. The problems and contradictory nature of economic security mechanisms used in the 1920s are revealed.
\end{abstract}


Keywords: economic security, economic crimes, Cheka, OGPU, NEP.

For citation: Bogdanov S.V., Ostapuk V.G. 2020. State security bodies of soviet Russia and ensuring economic security of the country, 1921-1928: mechanism, problems, contradictions (on materials of Kursk and Voronezh provinces). NOMOTHETIKA: Philosophy. Sociology. Law series. 45 (2): 307-314 (in Russian). DOI 10.18413/2712-746X-2020-44-2-307-314

\section{Введение}

Особое внимание российских властных элит к сфере экономической безопасности государства проявлялось на самых различных этапах развития страны. Безусловно, на формирование государственной концепции, а также комплекса практических мер по обеспечению устойчивого развития социально-экономической сферы и минимизации потенциальных угроз на данном направлении оказывали влияние многочисленные обстоятельства как внутреннего, так и внешнего характера. Поэтому обращение к основным этапам становления и развития государственной политики и правового обеспечения экономической безопасности имеет как теоретический, так и практический интерес для современных исследователей.

Обращение к достаточно обширной литературе, посвященной проблемам экономической безопасности, позволяет выявить следующие наиболее характерные черты. Рассмотрение вопросов экономической безопасности государства и общества осуществлялось преимущественно через призму противодействия преступлениям в сфере экономики. Так уже на рубеже XIX-XX столетий появляются первые работы российских авторов по данной проблематике [Тарновский, 1889, 1898, 1900]. Характеристика должностных преступлений среди российского чиновничества была представлена в работах Н.Д. Сергеевского [1890], М.И. Фридмана [1905], Ф.П. Купчинского [1908], П. Берлина [1910].

Период Гражданской войны и военной интервенции прервал поступательное развитие отечественной правовой мысли, посвященной изучению различных проявлений преступлений в сфере экономики. Однако переход к нэпу в начале 1920-х гг. вновь обострил интерес среди специалистов к феномену экономической преступности - теперь уже в советском обществе. Наиболее плодотворно на данном направлении работали Н. Яковченко [1925], Н.М. Полянский [1926], В. Ширяев [1926], М. Анцелович [1926], И.С. Кондурушкин [1927].

Весьма тщательному анализу в работах А.И. Потяева [1925], П.Н. Кумыкина [1927] были подвергнуты преступления, связанные с контрабандой. Это явилось закономерным следствием оживления внешнеэкономической деятельности, а также нормализации внутренней торговли.

Безусловно, одной из самых ярких работ того периода, посвященных различным криминальным проявлениям в сфере экономики, является работа известного советского партийного публициста Ю. Ларина [1927], которая в концентрированном виде представляла взгляды партийного руководства на данные проблемы.

\section{Особенности воспроизводства экономических преступлений в период нэпа}

По мере разрастания очагов Гражданской войны и сопротивления свергнутых социальных групп большевистское руководство активизирует свою деятельности по совершенствованию слаженности работы «карающего органа революции» - Всероссийской Чрезвычайной Комиссии по борьбе со спекуляцией и саботажем [Богданов, Ельчанинов, 2017].

На протяжении 1919 - первой половины 1920 гг. Орграспредотдел ЦК РКП(б) постоянно ориентировал местные партийные комитеты усилить их совместную деятельность с территориальными органами ВЧК по выявлению и своевременному пресечению фактов шпионажа, саботажа, должностных преступлений, дезертирства и антисоветских настроений. При этом количество документов, подлежащих отправке в территориальные органы ВЧК, имело тенденцию к нуклонному увеличению [Образование и деятельность..., 1961 ]. 
Переход к нэпу способствовал катализации огромного числа противоречий советского общества, которые в годы Гражданской войны и военной интервенции были загнаны вглубь, но вовсе не уничтожены. Наряду с многочисленными кадровыми перестановками на уровне губерний в центральном ведомстве было вновь реорганизовано ИНФО в составе обновлённого Секретно-оперативного управления ОГПУ ${ }^{1}$.

Окончание Гражданской войны и провал военной интервенции имели одним из своих следствий укрепление авторитета большевистского правительства, но это вовсе не означало, что страна вступала в период мирного процветания. Напротив, стремительный отказ от политики «военного коммунизма» и переход к нэпу способствовали развязыванию большого количества проблем и противоречий, в том числе в сфере обеспечения экономической безопасности государства, для решения которых требовались принципиально иные средства, методы и подходы.

Наглядным противоречием нового экономического курса явилось провозглашение свободы торговли с одной стороны, и резкий рост «мешочничества» - своеобразного рецидива периода «военного коммунизма», когда отдельные городские жители обменивали на дефицитные промышленные товары столь необходимые селянам продукты питания, с другой. Последние доставлялись в города и по спекулятивным ценам сбывались городским жителям. Голод 1921 г., разразившийся в Поволжье, послужил толчком для массовой спекуляции хлебом, которая спровоцировала рост цен на продовольствие в июне 1921 г. в тех губерниях, где отмечался приток беженцев из голодных территорий. Не осталась в стороне от массового распространения спекуляции и Курская губерния ${ }^{2}$.

В экономической сфере, свобода предпринимательской деятельности способствовала реализации трудового потенциала наиболее активной и предприимчивой части населения страны, многие из которых ещё помнили оживленные рынки, разнообразную торговлю и частные предприятия времен царской России. Не случайно в беспрецедентно сжатые сроки в нэповской России был ликвидирован товарный голод и былой дефицит товаров. В отношении частника сошлемся на выдержку из выступления одного из видных партийных идеологов 1920-х гг. Ю. Ларина: «Я предлагаю открыто заявить, что мы буржуазию расстреливаем и будем расстреливать и впредь. Советская Республика есть боевое государство, которое истребляет своих противников, а не заботится о перевоспитании Рябушинских» [Третья сессия ВЦИК..., с. 85].

Анализ государственной политики в отношении частного предпринимательства свидетельствует о ее неустойчивости, что проявилось в чередовании как периодов его поощрения, так и всевозможных ограничений. Нестабильность существования предпринимательской деятельности в 1920-е гг. способствовало уходу ее «в тень», смыканию с уголовной преступностью.

В мае 1923 г. начальником Валуйской милиции Воронежской губернии было получено инструктивное письмо, согласно которому следовало незамедлительно провести переучет всех частных торговцев хлебом, особо выделив среди этого перечня тех лиц, которые были внесены губернским исполнительным комитетом в список как злостные нарушители государственного ограничения цен на хлеб ${ }^{3}$.

Спустя два месяца, в постановлении Валуйского УИК за № 17 от 4.07.1923 предписывалось: «...в связи с неудовлетворительными видами на урожай и удержанием производителями для собственной потребности имеющихся остатков хлеба урожая 1923 г. на тер-

${ }^{1}$ Центральный архив Федеральной службы безопасности Российской Федерации (далее ЦА ФСБ РФ). Ф. 1. ОП. 5. Д. 157. Л. 70.

${ }^{2}$ ЦА ФСБ РФ. Ф. 1. Оп. 5. Д. 387. Л. 437.

${ }^{3}$ ГАБО. Ф. Р-384. Оп. 1. Д. 6. Л. 107. 
ритории уезда замечаются затруднения в снабжении хлебом потребляющей части населения. В связи с этим в обязанности милиции и финансовых инспекторов вменяются регулярные обследования рынков и базаров в целях выявления фактов спекуляции хлебом» ${ }^{1}$.

С середины 1920-х гг. негативное отношение советского государства к негосударственному сектору экономики и его носителям - частным предпринимателям - начинает усиливаться, а в социальном плане приобретает черты фактического социального вытеснения. В отчете руководителя Валуйской уездной милиции по итогам 1927 г. констатировалось: «В области работы по борьбе за ослабление влияния частника на кожсырьевом рынке привлечено за нарушение обязательного постановления № 23 в административном порядке 106 человек, на коих наложено штрафа 985 рублей, каковой и взыскан; кроме того, в соответствии с постановлением УИКа от 16.12.1927 за № 43/72 Милиция принимала активное участие по оказанию содействия Комиссии по обследованию кожевенных предприятий в уезде, в результате чего все частные предприятия закрыты, и выделанный товар поступил на местах ПО и сырье - кожсиндикату, в дальнейшем на эту работу обращено серьёзное внимание в области наблюдения за возможностью функционирования частных кожпредприятий» ${ }^{2}$.

В 1928 г. реализация государственной линии по вытеснению частника из сфер производства и торговли на территории Курской губернии вступила в свою решающую стадию. В начале февраля 1928 г. руководство Курского ОГПУ направило в адрес ЭКУ ОГПУ отчет о проведенной оперативной работе по вытеснению частника из экономики губернии.

Еще один из специфических факторов развития советского общества в период нэпа, который способствовал устойчивому воспроизводству широкого спектра преступлений экономического характера: хищениям государственного и общественного имущества, взяточничеству, различным злоупотреблениям служебным положением, всевозможным махинациям, являлась масштабная бюрократизация всей системы управления.

Несмотря на то, что основатель советского государства В.И. Ленин настойчиво призывал к борьбе с бюрократизмом на всех уровнях государственного управления, тем не менее эти призывы по большей части так и остались не реализованными на практике. Рост чиновничьего аппарата происходил не только в центре, но и на местах. Так, только для контроля над сбором продовольственного налога, принятого взамен продразверстки в марте 1921 г., в Курской губернии местное чиновничество сразу же увеличилось на 1000 человек $^{3}$.

Проблемы повышения эффективности функционирования всей системы управления в Курской и Воронежской губерниях неоднократно становились предметом многочисленных заседаний, совещаний и принимавшихся по их итогам решений. В качестве иллюстрации приведем выдержку из одного документа Курского ГИК от 14.02.1923, в котором отмечалось, что «...одной из причин слабости работы в волостях Советского аппарата являются неправильное распределение обязанностей между членами Волисполкома, а в иных случаях совершенное отсутствие разграничения деятельности каждого из них» ${ }^{4}$.

Политическая риторика большевистского руководства о «каждой кухарке, которая сможет управлять государством» к 1922-1923 гг., т.е. в начале нэпа, сменилась окончательным утверждением номенклатурного принципа. Правящей партии нужен был послушный и хорошо контролируемый государственный аппарат, служащие которого ре-

\footnotetext{
${ }^{1}$ ГАБО. Ф. Р-384. Оп. 1. Д. 7. Л. $48-48$ об.

${ }^{2}$ ГАБО. Ф. Р-1522. Оп. 1. Д. 30. Л. 22 об.

${ }^{3}$ ЦА ФСБ РФ. Ф. 1. Оп. 5. Д. 387. Л. 437.

${ }^{4}$ ГАБО. Ф. Р-384. Оп. 1. Д. 11. Л. 47 - 47 об.
} 
крутировались из числа преданных делу революции граждан. Такой подход способствовал созданию определенной привилегированной социальной группы населения. Их особый статус начинает закрепляться уже в 1920 г., когда Оргбюро ЦК РКП(б) соглашается с предложением Ф.Э. Дзержинского о недопустимости судебного разбирательства в отношении коммуниста без предварительного согласования с местной партийной организацией [Пашин, Богданов, 2004].

В начале февраля 1926 г. руководитель Валуйской уездной милиции направил секретный циркуляр подчиненным ему начальникам волостных милиций, в котором в кратчайшие сроки «приказывалось немедленно передать ему секретной почтой все заведённые уголовные дела в отношении членов РКП(б) и членов РЛКСМ» ${ }^{1}$.

Дальнейшие события показали, что по мере углубления нового экономического курса партийная элита советской России продолжала идти по пути дальнейшего совершенствования номенклатурной системы управления. Подтверждение тому является разосланная губернским партийным организациям секретная инструкция ВКП(б) с весьма красноречивым названием «О порядке привлечения к судебной ответственности ответственных работников-коммунистов» ${ }^{2}$.

Однако уже в первые годы перехода к нэпу среди различных представителей правящей партии ощущалась растерянность, а иногда и острое неприятие происходящего в советском обществе. В мае 1924 г. с трибуны ХІІІ съезда РКП(б) открыто звучало: «Болезненные, уродливые явления как в области идеологии, так и в области быта членов партии, морали - все они явственно обнаружились, гнойник прорвался» РКП(б)» [Тринадцатый съезд РКП(б)..., с. 279].

Безусловно, немаловажную роль в возникновении подобного социального негатива сыграли такие явления, как стремительная имущественная и социальная дифференциация, масштабная безработица, рост преступности. При этом низовое чиновничество оказалось практически на дне социальной пирамиды. Неслучайно возникновение многочисленных социальных соблазнов, явившихся порождением нэпа, явилось чрезвычайно привлекательным для отдельных представителей советских госслужащих. Это в свою очередь способствовало всплеску растрат и хищений государственной и общественной собственности, всевозможных махинаций и финансовых афер, коррупционных сделок, в которые по сведениям ОГПУ были втянуты представители самых различных государственных ведомств, даже Народного комиссариата по военным и морским делам $\mathrm{CCCP}^{3}$.

Характеризуя становление номенклатурной системы управления в Курской губернии в середине 1920-х гг. Е.В. Долженкова отмечает: «...соблазн нэпа породил ещё одну чрезвычайно острую проблему, затронувшую все вертикали власти и распадавшуюся на три взаимосвязанные составляющие: онэпивание, обрастание и излишества. Борьба с ними продолжалась все десятилетие, однако стремление к "залезанию в государственный карман" полностью изжить не удалось» [Долженкова, 2012, с. 25].

Анализ многочисленных сообщений территориальных органов ОГПУ о состоянии преступности на подведомственной территории свидетельствует о том, что среди регистрируемых преступлений все чаще встречаются упоминания о фактах взяточничества, которое поражает широкие слои советских служащих, начиная от низовых сельских советов и заканчивая чиновниками губернского масштаба. Объяснялось данное положение вещей преимущественно деятельностью враждебных элементов: «...материальная необеспеченность работников низового советского аппарата даёт достаточную возможность

\footnotetext{
${ }^{1}$ ГАБО. Ф. Р-384. ОП. 1. Д. 11. Л. 47-47 об.

2 Российский государственный архив социально-политической истории (далее РГАСПИ). Ф. 17. Оп. 34. Д. 6. Д. 137. Л. 58.

${ }^{3}$ РГАСПИ. Ф. 76. Оп. 2. Д. 16. Л. 43-76.
} 
проникновению в него кулацкого элемента. Материальная необеспеченность сельсоветов и волисполкомов делает их неработоспособными. Те же сельсоветы, в которых засел кулацкий элемент, непопулярны среди населения, так как всячески злоупотребляют своей властью. Взяточничество, пьянство, халатное отношение к делу, помощь кулакам сем[енным] материалом и даже агитация против Советской власти» ${ }^{1}$.

Еще одним из факторов, который способствовал значительному взлету различных проявлений противоправного поведения в советском обществе периода существования нэпа, являлся правовой нигилизм - отрицание норм права. Следует отметить, что данное явление не являлось исключительным приобретением 1920-х гг. Почва для данного негативного социального явления была заложена на протяжении всех предшествующих десятилетий, отличительной особенностью которых являлись масштабные катаклизмы: февральский, а затем октябрьский перевороты 1917 г., Гражданская война и военная интервенция. Поэтому к началу 1920-х гг. в советском обществе был накоплен мощнейший потенциал социальной деструкции, одним из проявлений которого явилось пренебрежительное отношение к праву, которое охватило широкие слои населения.

\section{Заключение}

Итак, рождение концепции экономической безопасности Советского государства, произошедшее сразу после 1917 г., было инициировано пролетарской властью. Естественно, это предопределило классовые приоритеты политики обеспечения экономической безопасности. В годы Гражданской войны указанная концепция была воплощена в политике «военного коммунизма». Но с провозглашением нового экономического курса в начале 1920-х гг. произошёл переход к иным регуляционным механизмам в сфере обеспечения экономической безопасности советского общества.

Однако по мере развития нэпа нарастали серьёзные проблемы и противоречия, которые во многом приобрели характер системных деформаций и проявились в следующем: широкое распространение правового нигилизма, снисходительное отношение к правонарушителям из пролетарской среды, наделение правовым иммунитетом представителей партийной номенклатуры. Данные тенденции деформировали систему обеспечения экономической безопасности советской России. Не случайно уже на рубеже конца 1920-х - начала 1930-х гг. партийно-государственное руководство СССР резко изменило устоявшуюся политику в этой сфере. На смену половинчатому и непоследовательному либерализму нэпа пришла новая тоталитарная государственность. В связи с этим принципиально иными стали основное содержание и методы поддержания экономической безопасности СССР.

\section{Список источников}

1. Третья сессия ВЦИК IX созыва. Стенографический отчет. 1923. М., Госиздат, 26.

2. Тринадцатый съезд РКП(б). 23-31 мая 1924 г. Стенографический отчет. 1924. М., Красная Новь, 765.

\section{Список литературы}

1. Анцелович М. 1927. Получение, дача и провокация взятки по УК редакции 1926 г. Еженедельник советской юстиции. 16: 465-496.

2. Берлин П. 1910. Русское взяточничество, как социально-историческое явление. Современный мир. 8: 48-56.

3. Богданов С.В., Ельчанинов П.М. 2017. Преступность и борьба с ней на территории Центрального Черноземья в 1920-е годы (на материалах Курской и Воронежской губерний): монография. М., РУСАЙНС, 274 с.

${ }^{1}$ ЦА ФСБ РФ. Ф. 2. Оп. 1. Д. 794. Л. 122-123. 
4. Долженкова Е.В. 2012. Отечественный исторический опыт в области подбора и расстановки руководящих кадров в 1920-е годы (На материалах Курского края): Автореф. дис. ...канд. ист. наук. Курск, 28 с.

5. Кондурушкин И.С. 1927. Частный капитал перед советским судом. Пути и методы накопления по судебным и ревизионным делам 1918-1926 гг. М.-Л., Гос. Изд-во, 240 с.

6. Кумыкин П.Н. 1927. Контрабанда и борьба с ней. М., Госюриздат, 302 с.

7. Купчинский Ф.П. 1908. «Герои» тыла. Очерки преступной деятельности чинов Интендантского ведомства во время русско-японской войны. СПб, Молодая мысль, 344 с.

8. Ларин Ю. 1927. Частный капитал в СССР. М.-Л., Гос. изд-во, 312.

9. Образование и деятельность местных чрезвычайных комиссий (1917-1921 гг.). Сб. док. и материалов. 1961. М., ВШ КГБ СССР, 377 с.

10. Пашин В.П., Богданов С.В. 2004. Партийная номенклатура (1917-1930-е годы): зарождение, развитие, безраздельное могущество. Белгород, 316 с.

11. Полянский Н.М. 1926. Должностные растраты. Их уголовное преследование. М., Правовая защита, 42 с.

12. Потяев А.И. 1925. Контрабанда и борьба с ней. М.: РИО НКВТ, 186.

13. Сергеевский Н.Д. 1890. О мошенничестве по русскому действующему праву. Юридическая летопись. Ноябрь: 373-448.

14. Тарновский Е.Н. 1898. Влияние хлебных цен и урожаев на движение преступлений против собственности в России. Журнал Министерства юстиции. 8: 73-106.

15. Тарновский Е.Н. 1889. Изменение преступности в различных общественных группах. Юридический вестник. 5: 32-54.

16. Тарновский Е.Н. 1900. Статистика преступности лиц дворянского сословия. Вестник права. 10: 14-41.

17. Фридман М.И. 1905. Наша финансовая система. Опыт характеристики. СПб., 476 с.

18. Ширяев В. 1926. Растрата и растратчики. Кн. 2. М., Изд-во НКВД, 194.

19. Яковченко Н. 1925. О борьбе с растратами. Рабочий суд. 49-50: 1855-1858.

\section{References}

1. Ancelovich M. 1927. Poluchenie, dacha i provokaciya vzyatki po UK redakcii 1926 g. [Receiving, giving and provoking a bribe according to the Criminal Code of 1926]. Ezhenedel'nik sovetskoj yusticii [Weekly of Soviet Justice]. 16: 465-496.

2. Berlin P. 1910. Russkoe vzyatochnichestvo, kak social'no-istoricheskoe yavlenie [Russian bribery as a socio-historical phenomenon]. Sovremennyj mir [Modern world]. 8: 48-56. (in Russian)

3. Bogdanov, S.V., El'chaninov P.M. 2017. Prestupnost' i bor'ba s nej na territorii Central'nogo CHernozem'ya v 1920-e gody (na materialah Kurskoj i Voronezhskoj gubernij) [Crime and the fight against it in the territory of the Central Black Earth Region in the 1920s (based on materials from the Kursk and Voronezh provinces)]: monografiya. M., RUSAJNS, $274 \mathrm{p}$.

4. Dolzhenkova E.V. 2012. Otechestvennyj istoricheskij opyt v oblasti podbora i rasstanovki rukovodyashchih kadrov v 1920-e gody (Na materialah Kurskogo kraya) [Domestic historical experience in the selection and placement of leading cadres in the 1920s (Based on materials from the Kursk Territory)]: Avtoref. dis. ...kand. ist. nauk. Kursk, 28 p.

5. Kondurushkin I.S. 1927. CHastnyj kapital pered sovetskim sudom. Puti i metody nakopleniya po sudebnym i revizionnym delam 1918-1926 gg. [Private capital before a Soviet court. Ways and methods of accumulation in judicial and revision cases 1918-1926]. M.-L., Gos. izd-vo, 240 p.

6. Kumykin P.N. 1927. Kontrabanda i bor'ba s nej. Praktika tamozhennogo dela [Smuggling and the fight against it]. M., Gosyurizdat, 302 p.

7. Kupchinskij F.P. 1908. «Geroi» tyla. Ocherki prestupnoj deyatel'`nosti chinov Intendantskogo vedomstva vo vremya russko-yaponskoj vojny ["Heroes" of the rear. Essays on the criminal activities of officials of the Quartermaster's Office during the Russo-Japanese War]. SPb, Molodaya mysl', 344 p.

8. Larin YU. 1927. CHastnyj kapital v SSSR [Private capital in the USSR]. M.-L., Gos. izdvo, $312 \mathrm{p}$.

9. Obrazovanie i deyatel'nost' mestnyh chrezvychajnyh komissij (1917-1921 gg.) [The formation and activities of local emergency commissions (1917-1921)]. Sb. dok. i materialov. 1961. M., VSH KGB SSSR, $377 \mathrm{p}$. 
10. Pashin V.P., Bogdanov S.V. 2004. Partijnaya nomenklatura (1917-1930-e gody): zarozhdenie, razvitie, bezrazdel'noe mogushchestvo [Party nomenclature (1917-1930s): origin, development, undivided power]. Belgorod, $316 \mathrm{p}$.

11. Polyanskij N.M. 1926. Dolzhnostnye rastraty. Ih ugolovnoe presledovanie [Official waste. Their criminal prosecution]. M., Pravovaya zashchita, 42 p. (in Russian) NKVT, 186.

12. Potyaev A.I. 1925. Kontrabanda i bor'ba s nej [Smuggling and the fight against it]. M.: RIO

13. Sergeevskij N.D. 1890. O moshennichestve po russkomu dejstvuyushchemu pravu [About fraud under Russian law]. YUridicheskaya letopis' [Legal Chronicle]. Noyabr': 373-448. (in Russian)

14. Tarnovskij E.N. 1898. Vliyanie hlebnyh cen i urozhaev na dvizhenie prestuplenij protiv sobstvennosti $\mathrm{v}$ Rossii [The influence of grain prices and yields on the movement of crimes against property in Russia]. ZHurnal Ministerstva yusticii [Journal of the Ministry of Justice]. 8: 73-106.

15. Tarnovskij E.N. 1889. Izmenenie prestupnosti v razlichnyh obshchestvennyh gruppah [Change in crime in various social groups]. YUridicheskij vestnik [Legal Bulletin]. 5: 32-54. (in Russian)

16. Tarnovskij E.N. 1900. Statistika prestupnosti lic dvoryanskogo sosloviya [Crime statistics of persons of the nobility]. Vestnik prava [Bulletin of law]. 10: 14-41.

17. Fridman M.I. 1905. Nasha finansovaya sistema. Opyt harakteristiki [Our financial system. Experience characteristics]. SPb., $476 \mathrm{p}$.

18. SHiryaev V. 1926. Rastrata i rastratchiki [Waste and waste]. Kn. 2. M., Izd-vo NKVD, 194.

19. YAkovchenko N. 1925. O bor'be s rastratami [On the fight against waste]. Rabochij sud [Working court]. 49-50: 1855-1858.

\section{ИНФОРМАЦИЯ ОБ АВТОРАХ}

Богданов Сергей Викторович, доктор исторических наук, доцент, профессор кафедры административного права и процесса Белгородского государственного национального исследовательского университета, Белгород, Россия

Остапюк Владимир Григорьевич, кандидат юридических наук, доцент, заведующий кафедрой административного права и процесса Белгородского государственного национального исследовательского университета, Белгород, Россия

\section{INFORMATION ABOUT THE AUTHORS}

Sergey V. Bogdanov, doctor of historical Sciences, associate Professor, Professor of the Department of administrative law and procedure, Belgorod state national research University, Belgorod, Russia

Vladimir G. Ostapyuk, candidate of law, associate Professor, head of the Department of administrative law and procedure of the Belgorod state national research University, Belgorod, Russia 